\title{
PENGUATAN ODHA TRANSPUAN KOTA DENPASAR DAN BULELENG DALAM KESEHATAN MASYARAKAT PEDULI WARIA
}

\author{
Nazrina Zuryani ${ }^{1}$ Putu Nomy Yasintha ${ }^{2)}$ M Adityanandana ${ }^{3)}$ Ni Made Anggi Sastri \\ Mahadewi $^{4}$ Ni Luh Nyoman Kebayantini ${ }^{5}$ Gede Kamajaya ${ }^{6}$
}

\author{
1,2,3,4,5 Universitas Udayana' \\ 1nazrinazuryan@unud.ac.id
}

\begin{abstract}
ABSTRAK
Workshop penguatan ODHA Transpuan ini berangkat dari permasalahan diskriminasi yang acap kali menimpa kelompok LGBT dan ODHA. Transpuan atau lebih dikenal sebagai waria adalah transfer gender dari jenis kelamin pria kepada perempuan. Mereka sering kali malu atau dipermalukan untuk berkiprah di masyarakat \{terutama bagi ODHA (Orang dengan HIV/Aids)\}. Di kota Singaraja telah terbentuk Wargas, yaitu organisasi Transpuan yang aktif mengembangkan modal sosial dan modal kulturalnya di masyarakat. Kota Denpasar memiliki tiga unit lembaga resmi penjangkau ODHA yaitu Gaya Dewata, Yayasan Kerti Praja dan Spirit Paramacita. Jumlah Transpuan dengan ODHA di Kota Denpasar diperkirakan 40 orang dan di Kota Singaraja diperkirakan 11 orang. Mereka perlu diproteksi dari stigma masyarakat dalam wadah jangkau yang lain dan bersifat sosial kemasyarakatan agar pola komunikasi mereka lebih kondusif dan masyarakat lebih menerima eksistensi mereka. Pelatihan tata rias Tengkuluk Lelunakan selama 5 jam terlaksana dengan menghadirkan kelompok Warcan dan Perwaron di Salon Agung pada anggal 13 Juli 2019. Ibu Agung sebagai pemilik salon yang terkenal dengan Payas Agung dan Tengkuluk Lelunakan telah memfasilitasi mereka untuk belajar tata rias tengkuluk lelunakan. Kelompok waria kota Denpasar difasilitasi untuk tampil dalam acara budaya atau festival lainnya, seperti yang sudah dilakukan oleh Wargas di kota Singaraja. Namun korespondensi dengan Kepala Dinas Kebudayaan Provinsi Bali di ruang kerja dan dengan Pemrakarsa Sanur Village Festival di hotel Griya Santrian belum membuahkan hasil. Workshop tengkuluk lelunakan bagi ODHA transpuan bertujuan agar masyarakat menerima mereka dan akhirnya mampu mendapatkan akses berbagai fasilitas untuk tampil di area publik utamanya dalam festival di kota Denpasar.

Kata kunci: Transpuan, ODHA, diskriminasi LGBT, Denpasar, Singaraja
\end{abstract}

\begin{abstract}
This workshop on strengthening Transwomen with HIV/Aids (ODHAT) started from the issue of discrimination that often afflicts the LGBT and ODHATgroups. Transgender women or better known as waria are gender transfers from male to female. They are often embarrassed or humiliated to take part in society \{especially for ODHA (People with HIV/Aids)\}. In the city of Singaraja, Wargas have been formed as Transwomen organization that is actively developing their social and cultural capital in the community. Denpasar City has three units of official outreach institutions for LGBT, namely Gaya Dewata, Kerti Praja Foundation and Spirit Paramacita. The number of Transwomen with ODHA in Denpasar City is estimated at 40 people and in Singaraja City it is estimated at 11 people. They need to be protected from the stigma of society in other reachable and social media so that their communication patterns are more conducive and the community is more accepting of their existence. The 5-hour Tengkuluk Lelunakan make-up training was carried out by presenting the Warcan and Perwaron groups at Salon Agung on July 13, 2019. Ibu Agung as a salon owner who is famous for Payas Agung and Tengkuluk Lelunakan has facilitated them to learn tengkuluk lelunakan make-up. Denpasar city transgender groups are facilitated to perform in cultural events or other festivals, as has been done by Wargas in Singaraja city. However, correspondence with the Head of the Bali Provincial Culture Service in the office and with the initiator of the Sanur Village Festival at the Griya Santrian hotel has not produced results. The tengkuluk Lelunakan workshop for transwomen with ODHA aims to make the community accept them and finally be able to get access to various facilities to perform in public areas, especially in festivals in the city of Denpasar.
\end{abstract}

Keyword: transwomen, ODHAT, LGBT discrimination, Denpasar, Singaraja 


\section{PENDAHULUAN}

Pada umumnya, topik-topik yang berhubungan dengan LGBT dan transpuan dilarang sebagai bahan ajar maupun diskusi di lingkungan pendidikan baik di tingkat sekolah dasar hingga menengah dan juga level pendidikan tinggi di Indonesia. Fenomena marjinalisasi terhadap kelompok LGBT dan transpuan dipelihara dan diperparah oleh elite politik dan pemerintah melalui berbagai pernyataan di berbagai media massa dan media sosial dan tindakan diskriminatif lainnya. Pada Januari 2016 lalu contohnya, Menteri Riset dan Teknologi M Natsir melarang keberadaaan Support Group and Resource Center on Sexuality Studies (SGRC) di kampus Universitas Indonesia (UI) yang menawarkan konseling bagi kelompok LGBT (Batubara 2016). Analisis media yang dilakukan oleh Ida (2010) menunjukkan bahwa pemberitaan media massa juga cenderung memberikan persepsi negatif terhadap kelompok LGBT dan transpuan. Tidak mengejutkan ketika survey yang dilakukan oleh SMRC menyebutkan bahwa 87,6\% masyarakat menilai kelompok LGBT merupakan ancaman (Sani 2018). Survey tersebut merupakan afirmasi dari apa yang diusulkan oleh Kali (2013: 9) dimana power dan knowledge melahirkan suatu wacana seksualitas yang pada akhirnya membentuk realita yang diskriminatif. Diskriminasi bukan hanya dialami oleh LGBT tetapi juga lemahnya toleransi komunitas tertentu kepada orang dengan HIV/AIDS (Odha). Apa yang dikatakan orang sebagai stigma kepada Odha seringkali tidak disadari melekat pada banyak lapis masyarakat. Apa bila survey tentang LGBT menyebutkan kelompok ini sebagai ancaman, stigma ini sangat kuat melekat LGBT dengan Odha. Bagi orang awam, penularan HIV/AIDS sangat terkait dengan kelompok LGBT.

Mereka lupa bahwa HIV/AIDS mudah menular pada penasun (pengguna narkoba dengan jaum suntik). Beberapa anggota masyarakat awam tetap memvonis Odha dari kelompok LGBT dengan sangat keras. Namun tidak semua daerah menolak kehadiran kaum transpuan. Kota Singaraja sejak tahun 2007 telah menerima kehadiran kelompok Wargas, yaitu organisasi sosial kaum Waria yang menyebut untuk pertama kali dirinya sebagai Transpuan. Kelompok ini mengawali debut tampil di muka publik dengan berpartisipasi pada acara Buleleng Festival/Bulfest. Ajang Bulfest bagi kelompok transpuan di kota Singaraja menjadi trending bagi kehadiran penonton. Ketua Wargas, menyampaikan bahwa kehadiran anggota Wargas dalam perhelatan kota Buleleng di utara pulau Bali ini ditunggu-tunggu karena mampu berekspresi dengan berbagai kostum yang menarik. Mami SC sebagai ketua Wargas mengungkapkan bahwa selama bertahun-tahun anggota Wargas menjadi bagian dari Bulfest, dianjurkannya kelompok Transpuan dari kota lain bergerak untuk tampil dalam perhelatan kota sekelas Denpasar. Diskusi dengan ketua Wargas ini berlanjut dengan anggota Wargas lain dan pengurus organisasi yang mengelola terapi ARV bagi anggota transpuan pengidap HIV dan AIDS di Bali Utara. Koordinatornya menyebut bahwa satu etika organisasi mereka adalah tidak menyebarkan data pengidap HIV/AIDS yang menjadi anggota Wargas. Mereka sangat ingin keutuhan dan pembelaan kepada anggota Transpuan menguat. Bagi pengelola Wargas, orang dengan HIV/Aids atau ODHA adalah segmen terlemah dalam organisasi mereka yang perlu diproteksi.

Diskusi di sekretariat Wargas ini bahwa menjadi boneka tontonan tidaklah menyenangkan perasaan terdalam kaum transpuan. Mereka ditempatkan bukan sebagai warga negara normal dan hanya mendapat pengakuan pada saat mereka menunjukkan tubuh berbeda mereka dalam balutan busana yang spektakular. Pembicaraan penonton yang tiada henti menunjukkan favoritisme pada aspek busana yang ditampilkan dalam parade itu tentu saja menimbulkan kebanggaan. Namun anggota Wargas sangat menyadari bahwa tubuh mereka yang bukan pria dan bukan pula wanita 
tetap menjadi sorotan bermakna sindiran atau cemoohan. Salah seorang anggota Wargas mempertanyakan tendensi orang-orang yang mengarahkan pencitraan publik golongan transpuan hanya berorientasi untuk menjual tubuhnya yang ambigu itu. Mereka berargumentasi bahwa apapun kondisi pilihan tubuh mereka, sangat penting kekuatan organisasi yang saling melindungi. Misalnya WARGAS dengan sangat kuat mengadvokasi ODHA yang menjadi anggotanya melalui sekretariat jangkauan pengobatan yang dimotori oleh Mba JSM. Begitu pula PERWARON yang sering mangkal di ruas jalan sepi Renon itu memiliki kemampuan memproteksi anggotanya yang ODHA dan acap kali ruang proteksi ini dimotori oleh mba VNY sebagai sekretarisnya. Pada organisasi WARCAN, kebanyakan mereka berkumpul di satu bangunan dengan banyak kamar kost di barat kecamatan Ubung. Mereka saling menyayangi dan sering bertemu karena acap kali anggota yang tidak tinggal bersama mengalami diskriminasi. Misalnya sebut saja Mba IS yang memperlihatkan dokumen KIPEM dengan harga Rp. 500.000 yang harus dibayarnya setiap 3 bulan. Koordinator WARCAN, mba KRSM sangat menyayangkan kondisi diskriminatif ini. Sejauh diskusi berlangsung, Mba IS adalah ODHA dan pecalang yang memaksanya membayar lebih banyak (pendatang lain sebanyak Rp. 300.000/triwulan) itu mengetahui bahwa mba IS adalah ODHA (lihat Foto dokumen KIPEM yang ditunjukkan oleh mba IS). Sikap pecalang yang menakuti-nakuti mba IS ini merupakan bukti diskriminasi alat pengamanan desa (pecalang) kepada kelompok LGBT.

Foto No. 1: Dokumen KIPEM dengan jumlah dana yang ditulis tangan oleh Pecalang

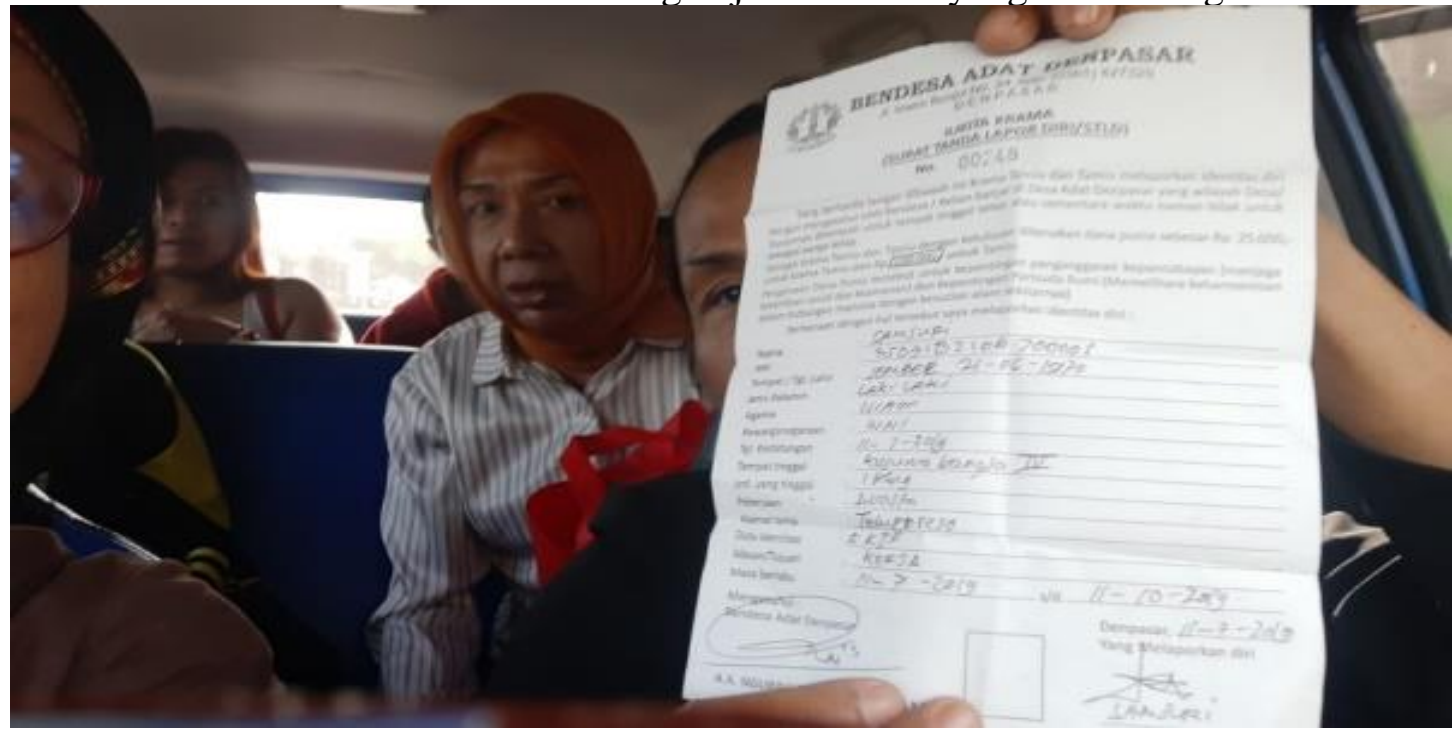

Sumber: Koleksi Pribadi Nazrina Zuryani: 2019

Organisasi kelompok transpuan memiliki peranan penting dalam melindungi dan memberikan dukungan terhadap anggotanya yang terinfeksi HIV/AIDS. Organisasi kelompok transpuan dalam penelitian ini, yaitu WARGAS, WARCAN, dan PERWARON berfungsi sebagai fasilitator dan pelindung bagi transpuan dengan HIV/AIDS yang tergabung dalam organisasi tersebut. Organisasi transpuan merupakan kepanjangan tangan dari pemerintah (Puskesmas) dan NGO HIV/AIDS dalam hal komunikasi, pendataan, konseling, pemberdayaan dan utamanya penyediaan akses kesehatan bagi transpuan dengan HIV/AIDS. Salah satu anggota organisasi transpuan WARCAN bahkan bekerja sebagai penyuluh HIV/AIDS di Puskesmas Badung dan 
merupakan salah satu anggota Kelompok Dukungan Sebaya (KDS) (wawancara pribadi, 26 Juni 2019). Penyuluh membantu ODHA secara umum termasuk transpuan untuk mendapatkan akses terapi HIV/AIDS, terutama distribusi obat antiretiroval. Selain itu, organisasi transpuan berfungsi sebagai pelindung dan memberikan dukungan emosional kepada transpuan dengan HIV/AIDS dalam menghadapi berbagai tekanan sosial dan psikologis melalui pelaksanaan kegiatan konseling dan pemberdayaan.

\section{METODE PENGABDIAN}

Pengabdian masyarakat ini merupakan suatu upaya pembelaan kepada kelompok masyarakat yang termarjinalkan. Tim Pengabdian menggunakan tiga tahap dalam pelaksanaanya.

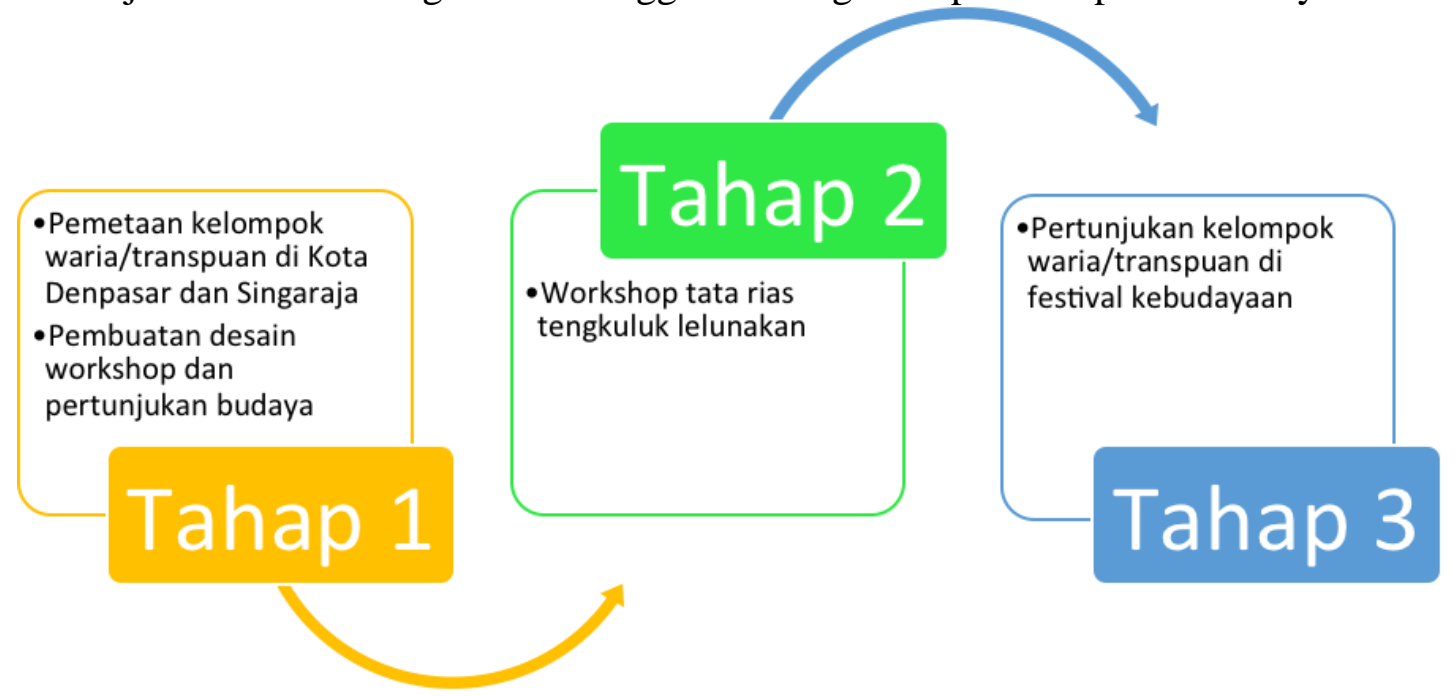

Upaya pembelaan tim pengabdian ini dimulai tahap 1 dengan mengenalkan ragam payas (tata rias) yang laku dan terus dikembangak di masyarakat yaitu tengkuluk lelunakan. Selain itu, tata rias bagi kelompok transpuan adalah cara mengesensikan diri mereka yang ingin tampil cantik seperti putri dan perempuan sesungguhnya sebagai tahap ke 2. Misalnya dengan kelompok Wargas telah terbangunkan saling komunikasi yang baik. Sayangnya untuk transpuan Kota Denpasar, tahap ke 3 gagal dilaksanakan karena penolakan pihak terkait (Kepala Dinas Kebudayaan Provinsi Bali di ruang kerja dan dengan Pemrakarsa Sanur Village Festival di hotel Griya Santrian) belum membuahkan hasil.

Foto No: 2. Kunjungan Pertama ke Singaraja dilanjutkan dengan kunjungan saat Bulfest

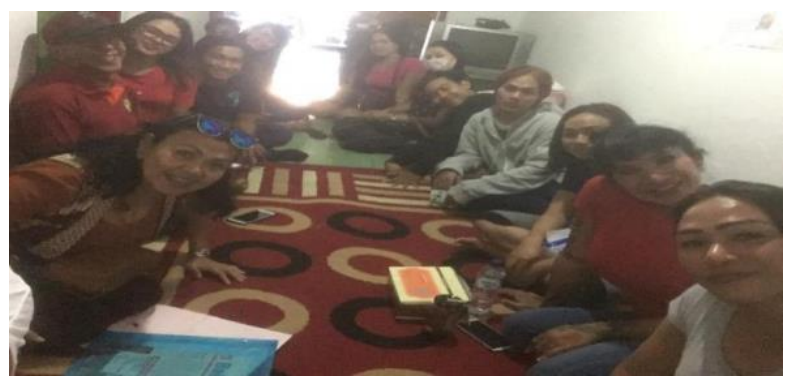

Sumber: Koleksi foto pribadi Nazrina Zuryani: 2019 


\section{Esensi Dan Perkembangan Tengkuluk Lelunakan}

Pengabdian masyarakat ini menggunakan metode partisipatif agar kelompok transpuan mampu menjaga jati diri Bali dengan mascot payas tengkuluk lelunakan. Tengkuluk lelunakan kian hari menjadi trend di kalangan masyarakat wanita Bali. Tengkuluk lelunakan banyak digunakan di acara-acara tradisional maupun acara kasual. Tengkuluk sendiri mulanya hanya di gunakan oleh wanita tua Bali agar rambut mereka tidak megambahan (terurai). Wanita tua di Bali tidak diperbolehkan untuk megambahan rambutnya atau mereka akan diasumsikan bisa ngeleak (black magic). Namun tidak akan merugikan bila kaum transpuan yang kebanyakan pendatang di kota Denpasar berketrampilan melakukan payas lelunakan.

Foto No: 3 Pelatihan Payas Lelunakan pada Salon Agung 31 Juli 2019

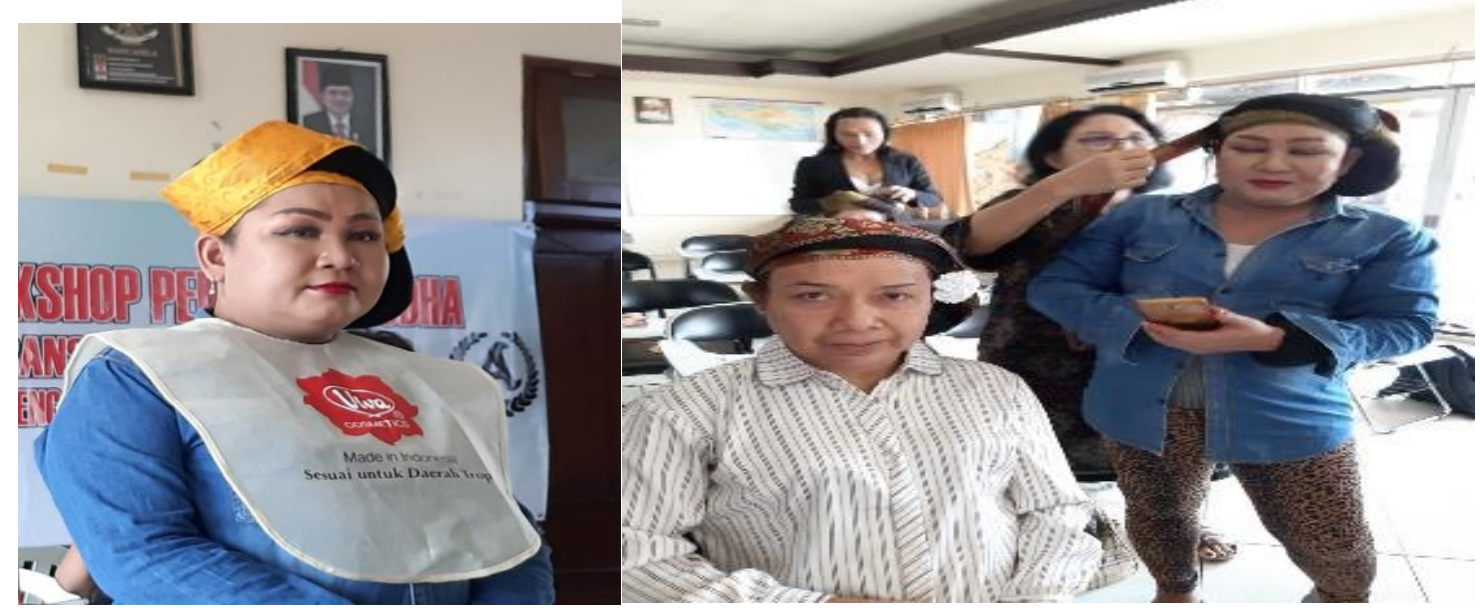

Sumber: Koleksi Pribadi Nazrina Zuryani: 2019

Bentuk dandanan perempuan Bali bervariasi dan masyarakat bisa menemukan lelunakan pada beberapa tarian Bali. Pada tahun 1960-an lelunakan ini dijadikan busana dalam tari tenun dan tari gegaboran. Sejak penggunaan lelunakan pada tarian ini, masyarakat Bali, Indonesia dan dunia menjadi lebih familiar terhadap tengkuluk lelunakan ini. Lelunakan sendiri merupakan pengembangan tengkuluk dalam bentuknya yang manis dan indah, karena kain yang dipakai bukan lagi handuk, melainkan selendang. Kain selendang yang digunakan untuk lelunakan ujungujungnya tertata rapi serta memiliki bukaan yang lebar, sehingga lebih melindungi kepala dan mengikat rambut yang tergelung lebih erat (Darsana, 2010).

Dahulu pada tahun 1960an tengkuluk hanya digunakan pada upacara pengabenan di daerah Denpasar/Badung. Namun kini selain kita dapat lihat dari tarian Bali, tengkuluk lelunakan juga dapat digunakan pada acara kasual. Pada 9 Desember 1996, busana tengkuluk lelunakan ini diseminarkan oleh Ketua TP PKK Bali sat itu Ibu Ida Ayu Asiawati Oka dan dijadikan busana untuk acara-acara resmi, seperti untuk menyambut tamu, untuk seka gambel, MC, paduan suara, dan acara lainnya. Pada perkembangan selanjutnya Ibu Asiawati Oka menyarankan bahwa setiap tamu atau pejabat (perempuan) yang berkunjung selalu dikenakan tengkuluk lelunakan. "Tradisi" ini kemudian dilanjutkan oleh Ibu Mas Beratha (almarhumah), dan Ibu Bintang Puspayoga saat menjabat Ketua TP PKK Denpasar. Busana tengkuluk lelunakan ini pun telah menjadi ikon Kota Denpasar, yang mana dalam malam grandfinal Pemilihan Teruna-Teruni Kota Denpasar yang 
digelar sejak tahun 2010 sampai sekarang, para finalis putrinya menggunakan busana ini (Tokoh, 2015).Kini semakin banyak pihak yang mulai mempromosikan payasan tengkuluk lelunakan ini. Salah satunya adalah Ibu A.A Ayu Ketut Agung sebagai pemilik Lembaga Kursus dan Pelatihan Salon Agung. Beliau secara aktif mensosialisasikan tengkuluk lelunakan kepada masyarakat. Beliau bekerja sama dengan TP PKK Denpasar, Kelompok Media Bali Post, dan salah satu merek kosmetik buatan Indonesia, di tahun 2009 Bu Agung menggelar "Lomba Tengkuluk Lelunakan" yang berhasil menyabet Rekor MURI.

Penggunaan tengkuluk lelunakan dahulu selalu menggunakan selendang Bali. Namun kini, payas tengkuluk lelunakan sudah disesuaikan dengan pakaian dan warna baju namun tetap berada dalam pakemnya. Walaupun penggunaan tengkuluk lelunakan bisa di katakana cukup sederhana di bandingkan payas Bali lainnya, namun pengerjaannya harus dilakukan oleh professional. Oleh karena itu pengenalan tengkuluk lelunakan kepada masyarakat luas harus tetap dilakukan. Selain sebagai kegiatan edukasi tradisi masyarakat Bali, hal ini juga dapat membantu untuk mempromosikan nilai budaya Bali kepada wisatawan lokal dan mancanegara.

\section{HASIL DAN PEMBAHASAN}

Korespondensi dengan Kepala Dinas Kebudayaan Bali di kantornya memperjelas marginalisasi kelompok Transpuan kota Denpasar. Ditambah lagi korespondensi dengan Penggagas Sanur Village Festival di Griya Santrian menolak kehadiran Transpuan dengan tengkuluk lelunakan. Pelatihan mepayas tengkuluk lelunakan selama 5 jam berlangsung pada tanggal 13 Juli 2019 diikuti oleh 31 orang transpuan dan 6 orang diantaranya ODHA serta 79 peserta lainnya. Salon Agung yang menggagas tengkuluk lelunakan menjadi tempat pelatihan yang langsung difasilitasi oleh ibu Agung (Dr. Dra. A.A. Ayu Ketut Agung, MM) pemilik salon sekaligus Direktur Lembaga Kursus dan Pelatihan Agung.

Foto No. 4: Kehadiran dalam Pelatihan Tata Rias Lelunakan
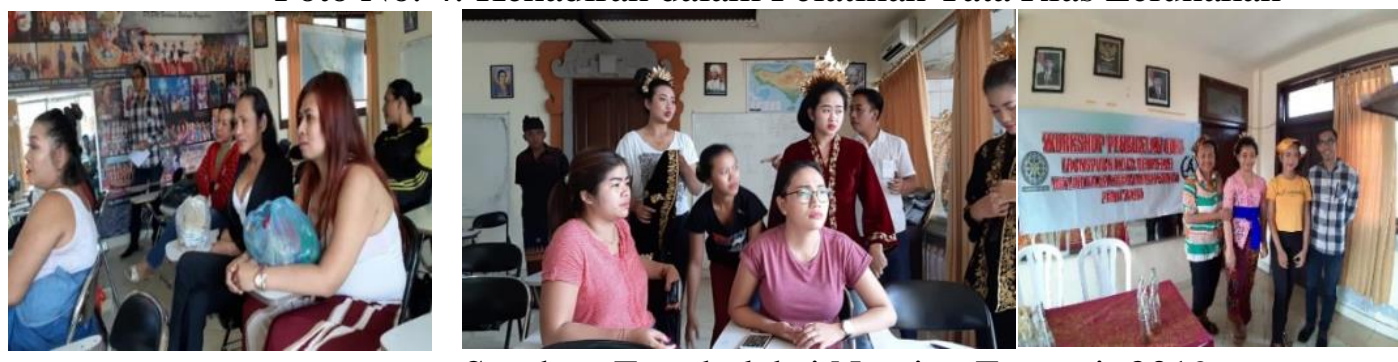

Sumber: Foto koleksi Nazrina Zuryani: 2019

Political will dari pemerintah dan elite Kota Denpasar dan Kota Singaraja dalam memberikan kesempatan bagi kelompok transpuan berekspresi di ruang publik sangat berbeda. Selama ini, kelompok transpuan di Kota Singaraja sudah diberikan ruang untuk berekspresi dan berinteraksi dengan masyarakat, terutama dalam pentas kebudayaan Buleleng Festival/Bulfest. Kelompok transpuan yang tergabung dalam Wargas bahkan menjadi tamu yang ditunggu-tunggu pada perayaan Buleleng Festival setiap tahunnya. Kelompok transpuan Wargas berkiprah melalui pertunjukan tari, gerak jalan dan parade fesyen dan mendapatkan apresiasi dan penerimaan dari warga Kota Singaraja, paling tidak dalam konteks seni dan budaya. Acara ini mirip parade negara jajahan Perancis yaitu seperti di New Orleans, Martinique, Haiti yang dikenal dengan sebutan Mardi 
Gras yang berasal dari Bahasa Perancis. Pun demikian, di tahun 2019, kelompok transpuan Wargas tidak turut tampil dalam acara kebudayaan Buleleng Festival. Hal ini menunjukkan komitmen pemerintah kabupaten Buleleng yang belum konsisten dalam mengupayakan penghapusan stigma terhadap kelompok transpuan di daerahnya. Terbukti marginalisasi kelompok Transpuan kota Denpasar masih berlanjut. Mereka harus membayar KIPEM dengan perlakuan diskriminatif. Dibandingkan dengan kota Singaraja, pemetaan tim pengabdian Unud dalam mensingkronisasi lembaga kebudayaan yang siap menerima kaum transgender untuk berkiprah dalam masyarakat belum berhasil. Walaupun pelatihan mepayas tengkuluk lelunakan berhasil, namun tahap ke tiga yaitu melibatkan para transgender dan ODHA dalam festival dan pesta kesenian Bali masih terhambat stigma dan diskriminasi.Sementara itu, kelompok transpuan di Kota Denpasar selama ini belum mendapatkan ruang untuk melakukan pertunjukan seni pada berbagai kegiatan budaya di Kota Denpasar, seperti Pesta Kesenian Bali maupun Sanur Village Festival. Pemerintah Provinsi Bali maupun Pemerintah Kota Denpasar belum bisa memberikan ruang berekspresi bagi kelompok transpuan di Pesta Kesenian Bali atau pesta kesenian lainnya. Salah satu alasan penolakan tersebut adalah karena Pesta Kesenian Bali bertujuan untuk melestarikan "nilai-nilai", "norma", dan "tradisi" Bali (Kepala Dinas Provinsi Bali, wawancara pribadi, 21 Mei 2019). Dari perspektif pemerintah, tujuan advokasi kelompok dan pemberdayaan kelompok transpuan tidak selaras dengan tujuan ini.

Keengganan untuk melibatkan kelompok transpuan pada pertunjukan kebudayaan juga ditunjukkan oleh tokoh-tokoh masyarakat di daerah Sanur. Menurut mereka, Sanur Village Festival merupakan event untuk mempromosikan pariwisata di Sanur dan nilai-nilai yang dipromosikan di pariwisata Bali atau Sanur berbeda dengan pariwisata di Bangkok atau Thailand yang memang melibatkan kelompok transpuan sebagai daya tarik wisatanya (Ketua Yayasan Pembangunan Sanur, wawancara pribadi, 28 Juni 2019). Berbagai korespondensi ini menunjukkan bahwa memang belum ada political will dari elite Kota Denpasar untuk mengubah stigma terhadap kelompok transpuan di Kota Denpasar. Kelompok transpuan tidak diberikan akses untuk terlibat dalam suatu pertunjukan seni yang biasanya merupakan ruang yang tidak tersubordinasi oleh narasi dualitas gender dan gender performativity yang klasik. Temuan ini merupakan salah satu jawaban mengapa kelompok transpuan di Kota Denpasar tidak begitu diterima di masyarakat selama ini.

\section{KESIMPULAN}

Di masa depan, para transpuan yang telah dilatih mepayas tengkuluk lelunakan ini akan dimasukkan sebagai peserta parade sekaligus menjadi penata rias. Mereka bisa memilih tampil atau melakukan tata rias lelunakan untuk keperluan pesta kota Denpasar dan sebagai sumber mata pencaharian. Selain itu mendorong pemerintah kota Denpasar dan provinsi Bali untuk merangkul kelompok waria/transpuan di daerah masing-masing selain para akademisi menulis di jurnal ilmiah agar marginalisasi tidak terjadi pada kelompok transpuan terutama stigma terhadap ODHA.

\section{UCAPAN TERIMA KASIH}

Tim pengabdian masyarakat FISIP Unud yang merupakan gabungan dosen Prodi Sosiologi, Administrasi Negara dan prodi Ilmu Politik mengucapkan terima kasih atas pemberian dana Udayana Mengabdi ini. 


\section{DAFTAR PUSTAKA}

Batubara, H. (2016, Januari 24) Menristek: Saya Larang LGBT di Semua Kampus, Itu Tak Sesuai Nilai Kesusilaan. detikNews

BPS Provinsi Bali. 2016. Bali dalam Angka Tahun 2016. Biro Pusat Statistik : Denpasar;

Darsana, I Ketut. 2010. Tata Busana Adat Bali. Diunduh dari: https://www.isi-dps.ac.id/artikel/tatabusana-adat-bali/ tanggal 20 September 2019.

Ida, R. 2010. Respon Komunitas Waria Surabaya Terhadap Konstruksi Subyek Transgender di Media Indonesia. Surabaya: Departemen Komunikasi FISIP, Universitas Airlangga, tahun, 23, 221-228

Kali, A. 2013. Diskursus Seksualitas Michel Foucault. Yogyakarta: Solusi Offset

Maridjan, Kacung, 2010, Sistem Politik Indonesia: Konsolidasi Demokrasi Pasca-Orde Baru, Penerbit Prenada Media Group : Jakarta;

Sani, A.F.I (2018, Januari 25) Survei SMRC: 87,6 Persen Masyarakat Menilai LGBT Ancaman. Tempo.co

Sanit, Arbi, 2010, Sistem Politik Indonesia, Penerbit Rajawali Press : Jakarta

Tokoh, -. Tengkuluk Lelunakan Kian Populer. Diunduh dari: https://www.cybertokoh.com/news/2017/08/29/6571/tengkuluk-lelunakan-kian-populer.html tanggal 20 September 2019.

Unit Penelitian FISIP Universitas Udayana, 2015. Laporan Hasil Penelitian Tahun 2010-2015. FISIP Unud : Denpasar

Yudah, A. A. P. 2017. Representasi Transgender dan Transeksual dalam Pemberitaan di Media Massa: Sebuah Tinjauan Analisis Wacana Kritis. Jurnal Kriminologi Indonesia, 9(2). 